\title{
Endovascular treatment of severe aortic stenosis in high and intermediate surgical risks patients
}

\author{
Kochkina $\mathrm{KV}^{1}$, Shtark $A A^{2}$, Protopopov $A V^{3}$ \\ Regional State Clinical Hospital; Krasnoyarsk Medical University by the name of prof. V.F. Voino-Yasenetckiy, Kras- \\ noyarsk, Russia \\ ${ }^{1}$ Kochkina KV, Invasive Cardiology Department, Krasnoyarsk State Clinical Hospital \\ ${ }^{2}$ Shtark AA, Cardiac surgery department, Krasnoyarsk State Clinical Hospital \\ ${ }^{3}$ Protopopov AV, PhD, Head of the Invasive Cardiology department, State Clinical Hospital, professor of Radiology \\ faculty of postdoc education of Krasnoyarsk Medical University by the name of prof. V.F. Voino-Yasenetcki
}

Abstract Aims. To evaluate the safety and efficacy of transcatheter aortic valve replacement with CoreValve bioprothesis in patients with severe aortic stenosis in high and intermediate surgical risk.

Methods and results. Data was prospectively collected from 81 patients with severe aortic stenosis, who underwent CoreValve implantation in one centre. After risk stratification 38 patients (46.9\%) were at high risk (STS score $>8 \%$ ). In 43 cases (53.1\%) patients were at intermediate STS score (STS score $>3$ and $<8 \%$ ), but due to different coexisting characteristics patients were not candidates for surgery. Technical success was achieved in all cases. All-cause hospital mortality was $6.2 \%$ ( 5 cases) generally, without statistical difference between two groups (10.5\% in high risk group, 4 patients; $2.3 \%$ in intermediate group, 1 patient). In two patients post-operation period was complicated by stroke (1 minor stroke, 1 major stroke; $2.5 \pm 1.7 \%$ of cases); in one case acute myocardial infarction developed 6 hours post CoreValve implantation (1.2\%); in one case acute renal failure developed, leading to death of the patient. No significant differences in cerebrovascular accidents and myocardial infarction between the different risk groups were observed throughout hospital period. During three years 56 patients $(72 \pm 5,0 \%)$ were available for follow up. Two patients died during follow-up: one patient died due to cancer progression ( 23 months after the implantation), one due to progression of chronic kidney insufficiency (18 months after implantation). No cerebrovascular or cardiac accidents were observed during follow up period.

Conclusion. In selected patients with intermediate surgical risk TAVR procedure with the use of CoreValve system have good clinical outcomes in hospitalisation period and long-term follow-up.

Key words Severe aortic stenosis, self-expanding valve, STS score risk evaluation.

\section{Abbreviations}

$\mathrm{BMI}=$ body mass index;

$\mathrm{CT}=$ computer tomography;
$\mathrm{PCl}=$ percutaneous coronary intervention;

STS = Society of Thoracic Surgeons;
TAVR $=$ transcatheter aortic valve replacement; TEE $=$ transesophageal echocardiography

\section{Introduction}

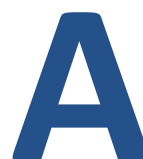

ortic stenosis is the most common valvular heart disease, which affects $2-4 \%$ of individuals older 65 years in USA and performs $43 \%$ of all valvular heart diseases in Europe ${ }^{1}$. Aortic stenosis increase in incidence with age, so one in eight people over the age of 75 have moderate to severe aortic valve disease ${ }^{2}$. Regarding the population aging, this condition becomes a serious public health problem. Medical management of severe aortic stenosis is a suboptimal strategy, may provide temporary symptom re- lief but is not effective long term ${ }^{3}$. Surgical aortic valve replacement is a gold standard recommended treatment, but patients with severe symptoms have been found to have a significantly higher operative mortality than those with no or only mild symptoms ${ }^{4}$. The use of a bioprosthetic valves can be an opportunity in treatment of elderly patients with severe stenosis $\left(<0.6 \mathrm{~cm}^{2}\right)$ or severe left ventricular dysfunction ${ }^{5-6}$. Approximately $30 \%$ of the patients with severe symptoms and coexisting conditions are not candidates for surgery ${ }^{7-9}$. Endovascular treatment of severe aortic stenosis - transcatheter aortic valve replacement (TAVR) proved to be 
effective and safe treatment in a group of inoperable and high-risk for surgery operation patients ${ }^{10-12}$ since 2002 , when the procedure was first performed ${ }^{13-14}$. Patients, undergoing TAVR procedure usually in advanced age, with serious comorbidity conditions (Logistic EuroSCORE $>20 \%$ ), and with contra indications to open surgery $^{15-18}$. 30-days mortality rate is reported on $5-20 \%$ level; myocardial infarction observed in 2-11\% of cases, stroke in 3-9\%, other vascular complications in $10-15 \%$ and AV-block in $4-30 \%$ of the patients. Mild to moderate paravalvular aortic valve regurgitation is present almost in half of the patients. The survival rate for 1 year with the use of transfemoral approach is $80-90 \% 19$-20.

Bioprosthesys CoreValve (Medtronic, USA) is a representative of third generation of artificial aortic valves for endovascular implantation. It is manufactured by suturing 3 valve leaflets and a skirt, made from a single layer of porcine pericardium, onto a self-expanding, multi-level, radiopaque frame made of Nitinol. It can be implanted from femoral, left subclavian, axillar approach. TAVR procedure with CoreValve system is performed in cathlab or hybrid room, by physicians who have received Medtronic CoreValve ${ }^{\mathrm{TM}}$ training, under TEE guidance and under general anesthesia.

The aim of the study is clinical-functional analysis of immediate and long-term results of TAVR with the use of CoreValve transcatheter aortic valve in patients with severe aortic stenosis at high and intermediate surgical risk as defined by a Society of Thoracic Surgeons (STS) risk score ${ }^{21}$.

\section{Methods}

Data was prospectively collected in the period 20112014 from 81 TAVR cases on the base of cardio-vascular center of Regional Clinical Hospital. Patients had severe aortic stenosis and cardiac symptoms for whom conventional surgery to replace the aortic valve was associated with high risk, or low risk in combination with contraindications for surgery. Two patients $(2.5 \%)$ had additional severe aortic regurgitation. In four cases combined valve disease was present: severe aortic stenosis and mild mitral stenosis. Two patients had relative contra indication for TAVR procedure - bicuspid aortic valve. All patients underwent precise evaluation for TAVR procedure with the use of CT angiography, echocardiography (transesophageal echo was used, if visualization on transthoracic echo was not appropriate), aortography in selected cases. Risk for surgical procedure was evaluated using STS risk score. Decision to a transcatheter or surgical strategy was made by heart team, that includes interventional cardiologist, cardiac surgeon, anesthesiologist and additional specialists in the case of pertinent comorbidities (nephrologist, endocrinologist). Written informed consent was obtained in all cases prior to the procedures.

In our center all TAVR cases are performed under general anesthesia, under TEE guidance during all the procedure.

All procedures were performed with transfemoral access. Four patients underwent access site closure with the Perclose device (Abbott Vascular Devices, Santa Clara, CA, USA) using pre-closure technique. In 77 cases standard arterial surgical cut-down was used, due to calcification (48 patients) and obesity (28 patients with $\mathrm{BM}>30$ ). According to the standard recommendations at the time of the procedure, patients were treated with $100 \mathrm{mg}$ of acetylsalicylic acid, a $600 \mathrm{mg}$ loading dose of clopidogrel, and unfractionated heparin 70-100 U/ kg.

After TAVR procedure patients were followed up at 1 , 6,12 months and once a year after 12 th months by means of a clinical visit or a standardized telephone interview. In the case of necessity additional hospital visit was administrated. Control TTE was performed every 6 months after the CoreValve implantation to assess valve function, peri-device flow and general echo parameters.

\section{Results}

All 81 patients were available for follow-up. Technical success was achieved in all cases. After risk stratification 38 patients $(46.9 \%)$ were at high risk (STS score $>8 \%$ ). In 43 cases (53.1\%) patients were at intermediate STS score (STS score $\geq 3$ and $\leq 8 \%$ ), but due to different coexisting characteristics patients were not candidates for surgery (Table 1 ).

Table 1. Patients, refused for surgery with low and intermediate STS score.

\begin{tabular}{|l|l|}
\hline Coexisting condition & Value \\
\hline Patients, refused for surgery, $\mathrm{n}(\%)$ & $43(53.1)$ \\
\hline Porcelain aorta, $\mathrm{n}(\%)$ & $27(62.8)$ \\
\hline Chest-wall irradiation, $\mathrm{n}(\%)$ & $11(25.6)$ \\
\hline Chest-wall deformation, $\mathrm{n}(\%)$ & $2(4.7)$ \\
\hline Frailty, $\mathrm{n}(\%)$ & $2(4.7)$ \\
\hline Mental health features, $\mathrm{n}(\%)$ & $1(2.3)$ \\
\hline
\end{tabular}

Patients in high risk group were significantly older, with lower body mass index, but in both groups prevalence of arterial hypertension was very high (>95\%) (Table 2). Significant symptoms of heart failure (NYHA III-IV) were prevalent in high risk group $(76.3 \%$ vs. $34.9 \%$, $p=0.03)$. Chronic obstructive pulmonary disease and renal failure were also more prevalent in high risk patients. In past medical history there was no difference in frequency of myocardial infarction, coronary arteries interventions between two groups, but high risk patients had more previous strokes ( $31.6 \%$ vs. $4.7 \%, p=0.006)$. Left ventricular ejection fraction was higher among intermediate risk patients $(58 \pm 2.16$ vs. $49.8 \pm 13.3, p<0.001)$. No difference in echocardiographic variables were find between two groups, mean aortic valve gradient was $45.2 \pm 14.7 \mathrm{mmHg}$ in high risk patients and $44.7 \pm 13.9$ $\mathrm{mmHg}$ in intermediate risk group ( $p=0.04)$; aortic valve area was $0.6 \pm 0.3 \mathrm{~cm}^{2}$ in high risk patients and $0.6 \pm 0.2$ $\mathrm{cm}^{2}$ in intermediate patients $(\mathrm{p}=0.7)$.

Significant coronary arteries disease was diagnosed in $57.9 \%$ in high risk group and in $41.9 \%$ in intermediate group ( $p=0.26,40$ patients in both groups). The decision about the time of the revascularisation (simultaneous or 
Table 2. Clinical characteristics, echo findings.

\begin{tabular}{|l|c|c|c|}
\hline Characteristic & $\begin{array}{c}\text { High risk group } \\
\text { (38 patients) }\end{array}$ & $\begin{array}{c}\text { Intermediate risk group } \\
\text { (43 patients) }\end{array}$ & $\mathbf{p}$ \\
\hline Age, years & $82.6 \pm 6.6$ & $74.8 \pm 8.4$ & $\mathrm{p}<0.001$ \\
\hline Male, $\mathrm{n}(\%)$ & $18(47.4)$ & $23(53.5)$ & $\mathrm{p}=0,19$ \\
\hline BMI (kg/m $\mathbf{m}^{2}$ & $23.9 \pm 5.4$ & $29.2 \pm 5.8$ & $\mathrm{p}<0.001$ \\
\hline STS score & $10.2 \pm 2.1$ & $4.1 \pm 1.8$ & $\mathrm{p}<0,001$ \\
\hline Diabetes Mellitus & $13(34.2)$ & $8(18.6)$ & $\mathrm{p}=0,16$ \\
\hline Arterial hypertension & $37(97.4)$ & $41(95.3)$ & $\mathrm{p}=0,53$ \\
\hline Hypercholesterolemia & $25(65.8)$ & $24(60.1)$ & $\mathrm{p}=0,39$ \\
\hline Heart Failure (NYHA III - IV), $\mathrm{n}(\%)$ & $29(76.3)$ & $15(34.9)$ & $\mathrm{p}=0,03$ \\
\hline Coronary arteries disease & $22(57.9)$ & $18(41.9)$ & $\mathrm{p}=0,26$ \\
\hline Prev. Myocardial infarction & $4(10.5)$ & $5(11.6)$ & \\
\hline Coronary arteries interventions - total number (\%) & & & \\
CABG & $1(2.6)$ & 0 & $\mathrm{p}=0,47$ \\
\hline PCI & $21(55.3)$ & $18(41.9)$ & $\mathrm{p}=0,3$ \\
\hline Peripheral Vascular disease, $\mathrm{n}$ (\%) & $13(34.2)$ & $10(23.3)$ & $\mathrm{p}=0,28$ \\
\hline COPD (any) & $15(39.5)$ & $5(11.6)$ & $\mathrm{p}=0,02$ \\
\hline Chronical kidney disease & $17(44.7)$ & $3(6.9)$ & $\mathrm{p}=0,001$ \\
\hline Cancer & $5(13.2)$ & $12(27.9)$ & $\mathrm{p}=0,04$ \\
\hline Atrial fibrillation & $10(26.3)$ & $11(25.5)$ & $\mathrm{p}=0,57$ \\
\hline Permanent pacemaker & $4(10.5)$ & $3(7.0)$ & $\mathrm{p}=0,44$ \\
\hline Previous stroke & $12(31.6)$ & $2(4.7)$ & $\mathrm{p}=0,006$ \\
\hline Echocardiography characteristics: & & & \\
Mean aortic-valve gradient, mm Hg & $45.2 \pm 14.7$ & $44.7 \pm 13.9$ & $\mathrm{p}=0,4$ \\
Aortic-valve area, (cm $\left.{ }^{2}\right)$ & $0.6 \pm 0.3$ & $0.6 \pm 0.2$ & $\mathrm{p}=0,7$ \\
\hline Pulmonary hypertension, $\mathrm{n}(\%)$ & $14(36.8)$ & $13(30.2)$ & $\mathrm{p}=0,41$ \\
Mitral regurgitation (moderate to severe) & $8(21.1)$ & $9(20.9)$ & $\mathrm{p}=0,6$ \\
\hline EF, \% \pm SD & $49.8 \pm 13.3$ & $58 \pm 2.16$ & $\mathrm{p}<0,001$ \\
\hline
\end{tabular}

staged procedure) was made individually in every patient, considering the significance of lesion and clinical condition. In $82.5 \%$ (33 patients) - PCl was performed at the time of diagnostic (ad-hock procedure) or before 1 month-2 weeks before planned TAVR, and in $17.5 \%$ of cases (7 patients) simultaneous $\mathrm{PCl}$ and TAVR was performed.

Post TAVR - need for permanent pacemaker was at the same for both groups - in 9 patients in high risk group $(23.7 \%)$, in 10 patients in intermediate group (23.3\%, $p=0.58)$.

All-cause hospital mortality was $6.2 \%$ (5 cases) generally, without statistical difference between two groups, probably due to the small amount of patients (10.5\% in high risk group, 4 patients; $2.3 \%$ in intermediate group, 1 patient). In two patients post-operation period was complicated by stroke (1 minor stroke, 1 major stroke; $2.5 \pm 1.7 \%$ of cases); in one case acute myocardial infarction developed 6 hours post CoreValve implantation (1.2\%); in one case acute renal failure developed, leading to death of the patient. No significant differences in cerebrovascular accidents and myocardial infarction between the different risk groups were observed throughout hospital period. During three years 56 patients $(72 \pm 5,0 \%)$ were available for follow up. Two patients died during follow-up: one patient died due to cancer progression (23 months after the implantation), one due to progression of chronic kidney insufficiency (18 months after implantation). No cere- brovascular or cardiac accidents were observed during follow up period.

\section{Discussion}

The performed analysis is based on a single-centre experience with patients undergoing TAVR in high and intermediate surgical risks, with the use of CoreValve selfexpanding system. All patients, included in analysis, were precisely discussed by heart team of our multidisciplinary hospital. The risk for surgical aortic valve replacement was counted with the use of STS score, as the most exact predictor of outcome, as it was recognised, that the logistic EuroSCORE overestimates the risk for adverse clinical outcomes $^{22}$. In big randomized trials, such as SURTAVI, STS score was chosen for risk evaluation of the patients ${ }^{23}$. Several conditions, such as porcelain aorta, chest wall irradiation or deformation, frailty making intermediate and low surgical patients contra-indicated for surgery. These factors are always discussed by a heart team, for choosing the appropriate treatment strategy. According to contemporary practice in Europe ${ }^{24}$, intermediate risk patients were included to our analysis. In several singlecentre and multi-centre studies patients in low surgical risks were also included ${ }^{24-25}$.

All cause death in our centre was $6.2 \%$ for all patients, which is similar to analysis, performed by Wenaweser et. al. ${ }^{26}$, where all cause death was $6.4 \%$. But in these study, patients were divided in three 
Table 3. Clinical outcomes at 30 days

\begin{tabular}{|l|c|c|c|c|}
\hline Hospitalization period & $\begin{array}{c}\text { All patients } \\
\text { (81 patients) }\end{array}$ & $\begin{array}{c}\text { High risk group } \\
\text { (38 patients) }\end{array}$ & $\begin{array}{c}\text { Intermediate risk group } \\
\text { (43 patients) }\end{array}$ & p \\
\hline All cause death, $\mathrm{n}(\%)$ & $5(6.2)$ & $4(10.5)$ & $1(2.3)$ & 0.16 \\
\hline Minor stroke, $\mathrm{n}(\%)$ & $1(1.2)$ & $1(2.6)$ & $0(0)$ & 0.47 \\
\hline Major stroke, $\mathrm{n}(\%)$ & $1(1.2)$ & $0(0)$ & $1(2.3)$ & 0.53 \\
\hline Myocardial infarction, $\mathrm{n}(\%)$ & $1(1.2)$ & $0(0)$ & $1(2.3)$ & 0.53 \\
\hline Acute renal failure, $\mathrm{n}(\%)$ & $1(1.2)$ & $1(2.6)$ & $0(0)$ & 0.47 \\
\hline Access cite complications, $\mathrm{n}(0)$ & $0(0)$ & $0(0)$ & $0(0)$ & \\
\hline
\end{tabular}

groups: low, intermediate and high risk patients. All cause mortality rate was lower in low risk patients and intermediate risk patients compared with high risk group. In our experience, statistically significant difference between intermediate and high risk patients was not achieved $(p=0.16)$, probably because of small amount of patients. All-cause death during hospitalisation was observed on a rate $2.3 \%$, what can be considered as a good result of implantation. Long-term results in intermediate group were not worse, compare with high risk group. We consider, that selected patients with intermediate surgical risk will have good clinical outcomes in hospitalisation period and long-term followup. Randomized trials, PARTNER II and SURTAVI should be completed, to prove, that TAVR procedure can be preferred for patients with intermediate surgical risk.

\section{References}

1. Singh IM, Shishehbor MH, Christofferson RD, Tuzcu EM, Kapadia SR. Percutaneous treatment of aortic valve stenosis. Clevel Clin J Med 2008 (11):805-812.

2. Nkomo VT, Gardin JM, Skelton TN, et al. Burden of valvular heart diseases: a population-based study. Lancet 2006;368:10051011.

3. Vahanian A, Alfieri O, Andreotti F, Antunes MJ, Barón-Esquivias $\mathrm{G}$, Baumgartner $\mathrm{H}$, et al. Guidelines on the management of valvular heart disease (version 2012): The Joint Task Force on the Management of Valvular Heart Disease of the European Society of Cardiology (ESC) and the European Association for CardioThoracic Surgery (EACTS). Eur Heart J 2012;33(19):2451-2496.

4. Society of Thoracic Surgeons. STS national database: STS U.S. cardiac surgery database: 1997, Aortic valve replacement patients: preoperative risk variables. Chicago: Society of Thoracic Surgeons, 2000. http://www.ctsnet.org/doc/3031.

5. Bonow RO, Carabello BA, Kanu C, et al. ACC/AHA 2006 guidelines for the management of patients with valvular heart disease: a report of the American College of Cardiology/American Heart Association Task Force on Practice Guidelines (writing committee to revise the 1998 Guidelines for the Management of Patients With Valvular Heart Disease): developed in collaboration with the Society of Cardiovascular Anesthesiologists: endorsed by the Society for Cardiovascular Angiography and Interventions and the Society of Thoracic Surgeons. Circulation 2006;114:e84-231.

6. Vahanian A, Baumgartner H, Bax, et al. Guidelines on the management of valvular heart disease: the Task Force on the Management of Valvular Heart Disease of the European Society of Cardiology. Eur Heart J 2007;28:230-68.

7. lung B, Cachier A, Baron G, et al. Decision-making in elderly patients with severe aortic stenosis: why are so many denied surgery? Eur Heart J 2005;26:2714-2720.

8. Varadarajan P, Kapoor N, Bansal RC, Pai RG. Clinical profile and natural history of 453 nonsurgically managed patients with severe aortic stenosis. Ann Thorac Surg 2006;82:2111-2115.
9. Bach DS, Siao D, Girard SE, Duvernoy C, McCallister BD Jr, Gualano SK. Evaluation of patients with severe symptomatic aortic stenosis who do not undergo aortic valve replacement. Circ Cardiovasc Qual Outcomes 2009;2:533-539.

10. Tom Kai Ming Wang, Janarthanan Sathananthan, Nicholas Chieng, et al. Aortic valve replacement in over 70- and over 80-year olds: 5 -year cohort study. Asian Cardiovascular \& Thoracic Annals 2014; 22(5) 526-533.

11. Thomas Pilgrim, Lars Englberger, Martina Rothenbühler, et al. Long-term outcome of elderly patients with severe aortic stenosis as a function of treatment modality. Heart 2014; 56:1-7.

12. Josep Rodés-Cabau, MD; John G. Webb, MD; Anson Cheung, $\mathrm{MD}$, et al. Transcatheter Aortic Valve Implantation for the Treatment of Severe Symptomatic Aortic Stenosis in Patients at Very High or Prohibitive Surgical RiskAcute and Late Outcomes of the Multicenter Canadian Experience. J Am Coll Cardiol 2010;55(11):1080-1090.

13. Cribier A, Eltchaninoff $H$, Bash A, et al. Percutaneous transcatheter implantation of an aortic valve prosthesis for calcific aortic stenosis: first human case description. Circulation 2002;106:3006-3008.

14. Cribier A, Eltchaninoff $H$, Tron $C$, et al. Early experience with percutaneous transcatheter implantation of heart valve prosthesis for the treatment of end-stage inoperable patients with calcific aortic stenosis. J Am Coll Cardiol 2004;43:698-703.

15. Grube E, Schuler G, Buellesfeld L, et al. Percutaneous aortic valve replacement for severe aortic stenosis in high-risk patients using the second- and current third-generation self-expanding CoreValve prosthesis: device success and 30-day clinical outcome. J Am Coll Cardiol 2007;50:69-76.

16. Lichtenstein SV, Cheung A, Ye J, et al. Transapical transcatheter aortic valve implantation in humans: initial clinical experience. Circulation 2006;114:591-596.

17. Ye J, Cheung A, Lichtenstein SV, et al. Six-month outcome of transapical transcatheter aortic valve implantation in the initial seven patients. Eur J Cardiothorac Surg 2007;31:16-21.

18. Walther T, Falk V, Kempfert J, et al. Transapical minimally invasive aortic valve implantation; the initial 50 patients. Eur J Cardiothorac Surg 2008;33:983-8.

19. Webb JG, Chandavimol M, Thompson CR, et al. Percutaneous aortic valve implantation retrograde from the femoral artery. Circulation 2006;113:842-50.

20. Grube E, Schuler G, Buellesfeld L, et al. Percutaneous aortic valve replacement for severe aortic stenosis in high-risk patients using the second- and current third-generation self-expanding CoreValve prosthesis: device success and 30-day clinical outcome. J Am Coll Cardiol 2007;50:69-76.

21. Shroyer AL, Coombs LP, Peterson ED, et al. The Society of Thoracic Surgeons: 30-day operative mortality and morbidity risk models. Ann Thorac Surg 2003;75:1856-1864.

22. Piazza N, Wenaweser $P$, van Gameren $M$, Pilgrim T, Tzikas A, Otten A, Nuis R, Onuma Y, Cheng JM, Kappetein AP, Boersma E, Juni $P$, de Jaegere $P$, Windecker S, Serruys PW. Relationship between the logistic EuroSCORE and the Society of Thoracic Surgeons Predicted Risk of Mortality score in patients implanted with the CoreValve ReValving system - a Bern-Rotterdam Study. Am Heart J 2010;159:323-329.

23. van Mieghem NM, Head SJ, van der Boon RM, Piazza N, de Jaegere PP, Carrel T, Kappetein AP, Lange R, Walther T, Windecker S, 
van Es GA, Serruys PW. The SURTAVI model: proposal for a pragmatic risk stratification for patients with severe aortic stenosis. Eurolntervention 2012;8:258-266.

24. Lange R, Bleiziffer S, Mazzitelli D, Elhmidi Y, Opitz A, Krane M, Deutsch MA, Ruge H, Brockmann G, Voss B, Schreiber C, Tassani P, Piazza N. Improvements in transcatheter aortic valve implantation outcomes in lower surgical risk patients: a glimpse into the future. J Am Coll Cardiol 2012;59:280- 287.

25. Moat NE, Ludman $P$, de Belder MA, Bridgewater $B$, Cunningham $A D$, Young CP, Thomas M, Kovac J, Spyt T, MacCarthy PA, Wendler O, Hildick-Smith D, Davies SW, Trivedi U, Blackman DJ, Levy
RD, Brecker SJ, Baumbach A, Daniel T, Gray H, Mullen MJ. Longterm outcomes after transcatheter aortic valve implantation in high-risk patients with severe aortic stenosis: the U.K. TAVI (United Kingdom Transcatheter Aortic Valve Implantation) Registry. J Am Coll Cardiol 2011;58:2130-2138.

26. Clinical outcomes of patients with estimated low or intermediate surgical risk undergoing transcatheter aortic valve implantation.Wenaweser P, Stortecky S, Schwander S, Heg D, Huber C, Pilgrim T, Gloekler S, O'Sullivan CJ, Meier B, Jüni P, Carrel T, Windecker S. Eur Heart J 2013;34(25):1894-905. 